\title{
Multidirectional wave transformation around detached breakwaters
}

\author{
Ilic, S, ${ }^{1}$, van der Westhuysen, A.J. ${ }^{2}$, Roelvink, D.J.A ${ }^{3}$, Chadwick, A.J. \\ ${ }^{1}$ Geography Department, Lancaster University, LA1 4YQ, UK, s.ilic@lancaster.ac.uk; \\ $+-44-1524510264$ \\ ${ }^{2}$ WL | Delft Hydraulics, P.O. Box 177, 2600 MH Delft, The Netherlands, \\ andre.vdwesthuysen@wldelft.nl \\ ${ }^{3}$ UNESCO-IHE Institute for Water Education, P.O. Box 3015, 2601 DA Delft, The \\ Netherlands, D.Roelvink@unesco-ihe.org \\ ${ }^{4}$ School of Engineering, University of Plymouth, Reynolds Building, Drake Circus, \\ Plymouth PL4 8AA, UK, A.Chadwick@plymouth.ac.uk
}

\section{Abstract}

The performance of the new wave diffraction feature of the shallow-water spectral model SWAN, particularly its ability to predict the multidirectional wave transformation around shore-parallel emerged breakwaters is examined using laboratory and field data. Comparison between model predictions and field measurements of directional spectra was used to identify the importance of various wave transformation processes in the evolution of the directional wave field. First, the model was evaluated against laboratory measurements of diffracted multidirectional waves around a breakwater shoulder. Excellent agreement between the model predictions and measurements was found for broad frequency and directional spectra. The performance of the model worsened with decreasing frequency and directional spread. Next, the performance of the model with regard to diffraction-refraction was assessed for directional wave spectra around detached breakwaters. Seven different field cases were considered: three wind-sea spectra with broad frequency and directional distributions, each coming from a different direction; two swell-sea bimodal spectra; and two swell spectra with narrow frequency and directional distributions. The new diffraction functionality in SWAN improved the prediction of wave heights around shore-parallel 
breakwaters. Processes such as beach reflection and wave transmission through breakwaters seem to have a significant role on transformation of swell waves behind the breakwaters. Bottom friction and wave-current interactions were less important, while the difference in frequency and directional distribution might be associated with seiching.

Keywords: wave refraction-diffraction, multidirectional waves, SWAN, detached breakwaters, wave transmission, beach reflection

\section{Introduction}

The advantage of detached breakwaters compared to more traditional shoreline structures is that they decrease the height of incoming waves and reduce offshore sediment losses. As they are mostly built in intermediate to shallow waters, the physical processes that may be involved in wave transformation around detached breakwaters include: shoaling; refraction; diffraction; energy dissipation due to sea bed friction and wave breaking; interaction of waves and currents; wave reflections from structures and beaches; wave transmission through and over permeable structures; and spectral evolution due to wave-wave interaction. Consequently, the wave energy is significantly reduced in the area immediately behind the breakwater, resulting in the development of depositional forms such as salients and tombolos.

Field measurements of waves around detached breakwaters are rare and hence little is known about the spectra transformation due to these structures. Although refractiondiffraction processes have the most important role, the effects of wave transmission through the breakwaters, reflection from the structures and beach, and wave dissipation are not known. The detached breakwater scheme at Elmer, West Sussex, offered an 
opportunity to measure directional wave transformation. Concurrent measurements of offshore and inshore directional spectra in the embayment between two breakwaters were conducted for almost a year (Chadwick et al., 1994). A wide range of recorded sea conditions (wind waves, swell waves and bimodal waves) will enable the investigation of the effects of different processes on directional spectra.

The prediction of the transformation of directional spectra around coastal structures has received little attention thus far (Goda, 1998). Most of the predictions and the validation of numerical models were primarily focused on the wave height distribution around structures. Besides, these models were used to simulate the wave transformation of a monochromatic plane wave. However, previous field and laboratory studies have shown that the diffracted wave heights in the lee of the breakwater can be underestimated if random multidirectional waves are represented by a single wave (Ilic et al. 2005, Goda, 2000, Mory and Hamm, 1997, Briggs at al., 1995).

The most frequently used linear diffraction-refraction models are wave transformation models based on the Mild Slope Equation (MSE) derived by Berkhoff (1972, 1976). Several authors have derived similar models or extended the model by the inclusion of further physical processes. An extensive review and background information to the MSE and related approaches can be found in Dingemans (1997). These models have been applied to the transformation of the regular waves as well as to the transformation of the real sea. Isobe (1987), Hurdle et al. (1989), Panchang et al. (1990), Grassa (1990), O’Reilly and Guza (1991), Ozkan and Kirby (1993), Li et al. (1993), amongst others, have each developed so called 'directional' models that operate by first discretising the spectrum into individual monochromatic directional components and 
then running each component in a separate model. Results from the segmental runs are superimposed in order to obtain estimates of statistical wave heights.

Ilic and Chadwick (1995) and Ilic (1999) applied Li's (1994) time parabolic model in a similar way to study the wave transformation around a scheme of shore-parallel breakwaters at Elmer. It was shown that the agreement between simulated and measured wave heights improved when 'directional' modelling was used. However, these kinds of models do not explicitly predict the directional spectrum, but give an estimate of the directionally integrated wave energy.

Alternatively, the effects of refraction-diffraction can be computed using phaseresolving models based on the Boussinesq type equations (e.g. Peregrine 1967, Madsen and Sorensen 1992, Wei and Kirby, 1995, Eldeberky and Battjes, 1996, Woo and Liu, 2004). They account for wave-current interactions and to some extent nonlinear effects and wave-wave interactions but require high spatial and temporal computational grid resolution. This makes them of less use for the simulation of wave transformation over larger areas such as shore-parallel breakwater schemes. Furthermore, most of these models need detailed time series of surface elevation and current information at the boundaries.

Spectral wave models, which are used to determine the wave conditions in coastal regions, can account for all relevant processes of wave generation, propagation and dissipation, except diffraction. Recently, a phase-decoupled refraction-diffraction approximation has been incorporated into the third generation spectral wave model SWAN (Holthuijsen et al. 2003), which has enabled its application to the simulation of wave transformation around structures. The incorporation of a diffraction approximation in a phase-averaged model such as SWAN has several advantages: 
computations over large areas are feasible; wave transformation of the directional wave spectra can be predicted; and processes such as dissipation and wave-wave interactions can be included (Holthuijsen et al. 2003).

The main aim of the present study is to evaluate new functionality of SWAN in the prediction of frequency and directional spectra around shore-parallel breakwaters. Furthermore, comparison of model predictions with measured frequency and directional spectra will help to identify the importance of various processes and their interaction on the evolution of the directional wave field. This paper is structured as follows. The model is briefly described in Section 2 . The model's ability to predict diffraction and the sensitivity of the model to numerical settings are given in Section 3. The results from a comparison with the field data are given in Section 4. Processes that influence the multidirectional wave transformation around detached breakwaters and the model's capabilities to predict them are discussed in Section 5. A summary and recommendations are given in Section 6.

\section{The phase-decoupled refraction-diffraction SWAN wave model}

The model used in this study is a shallow water spectral wave model SWAN (Booij et al., 1999) with the implemented diffraction-induced turning rate of the waves obtained from the Mild Slope Equation (Holthuijsen et al., 2003). The expressions for propagation speeds in the presence of the ambient currents such as the group velocity, the propagation speed in frequency space and the rate of directional turning are formulated in terms of the diffraction parameter $\delta_{\mathrm{E}}$ given by:

$\delta_{E}=\frac{\nabla \cdot\left(c c_{g} \nabla \sqrt{E}\right)}{\kappa^{2} c c_{g} \sqrt{E}}$ 
Here, $\mathrm{E}=\mathrm{E}(\omega, \theta)$ is the energy density of the waves; c is phase speed $(\omega / \kappa)$ where $\omega$ is angular frequency and $\kappa$ is the separation parameter determined from

$\omega^{2}=g \kappa \tanh (\kappa d)$

where $\mathrm{g}$ is gravitational acceleration and $\mathrm{d}$ is water depth.

The diffraction parameter $\delta_{\mathrm{E}}$ is approximated with a second-order central scheme based on the results from previous iterations. In order to speed up the convergence, the direction-integrated spectral density rather than frequency-direction spectral density was taken to calculate the diffraction parameter. A convolution filter was implemented for calculations of the gradients in the estimation of the diffraction parameter to smooth the wave field and avoid possible instabilities:

$E_{i, j}^{n}=E_{i, j}^{n-1}-0.2\left[E_{i-1, j}+E_{i, j-1}-4 E_{i, j}+E_{i+1, j}+E_{i, j+1}\right]^{n-1}$

where $i$ is a grid counter in $\mathrm{x}$-direction, the superscript $n$ indicates the iteration number of the convolution cycle. It has been suggested by Holthuijsen et al. (2003) that the number of convolution cycles should be at least $n=6$ for spatial resolution of $1 / 5-1 / 10$ of the wavelength to ensure numerical stability. The finite difference scheme in SWAN (Booij et al., 1999, Rogers et al., 2002) is not suited to approximate discontinuities and singularities in the diffraction-induced turning rate of the waves at the tips of the breakwaters or other obstacles. This can be dealt by applying under-relaxation (Zijlema and van der Westhuysen, 2005).

\section{Comparison with laboratory data}

The model's ability to predict diffracted directional spectra behind the structure was tested by using the laboratory measurements of Briggs et al. (1995). Additional 
sensitivity tests were performed to investigate the effect of spatial resolution and filtering on the model results.

\subsection{Physical model}

The physical model tests and measurements were performed in the CERC directional wave basin, were a semi-infinite breakwater was installed in the water depth of $0.46 \mathrm{~m}$ (Figure 1). One monochromatic and four directional spectral wave conditions of normal incidence were generated. The directional spectra represent four combinations of narrow and broad frequency distributions with narrow and broad directional spread (Table 1). The target incident spectral parameters in the TMA shallow water frequency distribution (Bouws et al., 1985) and the so-called wrapped normal directional spreading function (Borgman, 1990), used for each case are listed in Table 2. The values of $\gamma=2$ and $\gamma=20$ used in the physical model test represent extremes of wind-sea and swell conditions, respectively.

\subsection{Numerical model results}

Two different runs were performed with SWAN: without diffraction (SWAN1) and with diffraction (SWAN2) for four directional spectra. Twenty-two frequency and thirty-six directional components were used to simulate the incident directional spectra. Basic tests were conducted on a grid of $\Delta x=\Delta y=0.2 \mathrm{~m}(\mathrm{~L} / \Delta \mathrm{x}=11)$. Three different grid sizes of $\Delta x=\Delta y=0.1 \mathrm{~m} ; 0.3 \mathrm{~m}$ and $0.4 \mathrm{~m}$ were set up for sensitivity tests. To find an optimal number of convolution cycles, a series of simulations were conducted for each grid, in which the number of convolution cycles increased systematically.

The spectral diffraction coefficients were calculated as the ratio of the spectral significant wave height of diffracted spectrum $\left(\mathrm{H}_{\mathrm{m} 0 \mathrm{~d}}\right)$ in the lee of the breakwater to the 
spectral significant wave height for all simulations. This allows the customary presentation of diffraction diagrams and comparison with the measurements in transects S1, S2 and S3 (Figure1) and the model results by Walsh (1992). For all simulations, the rms difference was calculated using the formulation given by Walsh (1992)

rms difference $=\sqrt{\frac{\sum_{j=1}^{N}\left[\left(K_{d s p}\right)_{j}-\left(K_{d s m}\right)_{j}\right]^{2}}{N}}$,

where $\mathrm{K}_{\mathrm{dsp}}$ is the predicted spectral diffraction coefficient; $\mathrm{K}_{\mathrm{dsm}}$ is the measured spectral diffraction coefficient; and $\mathrm{N}$ is the number $(=27)$ of spectral diffraction coefficients computed for each wave condition.

The optimal number of convolution cycles for each numerically stable test was determined on the basis of the smallest rms difference. Figure 2 shows $r m s$ differences for the optimal number of convolution cycles and the optimal number of convolution cycles as a function of grid spacing for four different frequency and directional spectra. For a given grid spacing, the simulations of narrow frequency spectra require more convolution cycles to achieve stability than the simulations of broad frequency spectra. The rms differences are larger for narrow directional spectra than for broad directional

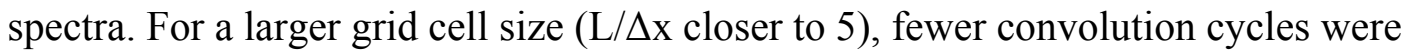

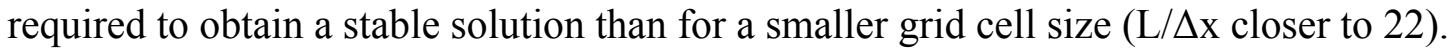
The lowest $r m s$ differences were found for $\mathrm{L} / \Delta \mathrm{x}$ around 11 for all except the N2 case. This figure can be used as a rough guide for a choice of the optimal number of steps for the convolution cycle. For example, for a broad frequency and directional spectrum and $\mathrm{L} / \Delta \mathrm{x}$ around 5 , only one convolution cycle is required. 
The rms differences for the optimal number of convolution cycles, for all grid sizes, were compared to the rms values given by Walsh (1992) and Ilic (1999) in Table 3. Walsh (1992) computed diffraction coefficients for each spectrum component as a function of frequency and direction at each measured position. The diffracted spectrum was then calculated by applying the diffraction coefficient to each spectrum component. Ilic (1999), as mentioned earlier, applied the 'directional' MSE numerical. The energy over all individual directional runs for each frequency component was summed and the zeroth moment wave heights were calculated. Spectral diffraction coefficients and rms differences were calculated as above.

The smallest $r m s$ differences, and hence best agreements, are obtained for wave conditions with a broad directional distribution. These predictions were better than those obtained by Walsh (1992) and Ilic (1999). Figure 3 shows an excellent agreement between the measured and simulated diffraction coefficients for the wave conditions B1. In contrast, SWAN made worse predictions of the diffraction coefficients for narrow frequency and directional spectra than the mild-slope model and Walsh's model (3.5 times larger $r m s$ ). The diffraction coefficients are underestimated in the lee of the breakwater and overestimated directly behind the tip of the structure for wave conditions N1 and N2 (Figure 4). Also, the difference between SWAN1 and SWAN2 results are larger for narrow directional spectra. Generally, SWAN2 predictions were closer to the measurements.

Increasing the grid size improved the predictions in the middle transect but worsened around the tip of the structure (Ilic et al., 2007). Implementation of under-relaxation improves results around the tip of the structure, reduces the number of convolution cycles needed for a stable solution and thus reduces the rms values. However, the under- 
relaxation parameters are case-dependent and need to be chosen with appropriate caution, as under-relaxation may introduce further instabilities. Hence, this was not considered in further study.

It can be concluded that the model, including diffraction effects, predicts the wave heights in the lee of the breakwater better than the model without diffraction effects. The model predicts the diffraction coefficients well (within 6-14\%) for the spectra with broad directional distributions, while for the spectra with narrow directional distributions the predictions are poor (within only $38-43 \%$ ). For narrow directional spectra the diffraction effect is larger as there is less energy propagating directly behind the breakwater (Briggs et al., 1995). For these cases, the extent of diffraction is not well reproduced by the model. This would appear to explain why rms differences are larger for narrow directional spectra.

\section{Multidirectional wave transformation in the field}

\subsection{Field experiment and data summary}

The field experiment took place at Elmer where a series of six detached breakwaters were built on a lower sandy beach just offshore of a steep (1/10) shingle beach (Figure 5). The coastline is subject to swell from the Atlantic and also to the wind waves generated locally along the English Channel. The tidal range varies from 2.9-5.3m on neap and spring tides.

Offshore wave directional spectra were measured by an array of six pressure transducers, which was deployed $650 \mathrm{~m}$ offshore and about $500 \mathrm{~m}$ from the completed breakwater scheme (location $\mathrm{O}$ in Figure 5). Inshore wave directional spectra were measured using a star of four surface-piercing wave staffs at location $\mathrm{S}$ in Figure 5 
(Chadwick et al., 1995). In addition, two satellite wave staffs were deployed, in the gap (location $\mathrm{G}$ in Figure 5) and in the lee of the breakwater (location L in Figure 5), for the whole duration of the field campaign.

The non-phase locking MLM method was applied in a directional analysis of the pressure and surface elevation measured by the offshore and inshore arrays respectively. The choice of method followed the recommendations of Huntley and Davidson (1998) and an evaluation of the method with the field data measured at Elmer by Ilic et al. (2000) and Chadwick et al. (2000).

Following Dingemans et al. (1984), a set of data for the numerical model validation was chosen on the basis of following criteria (Ilic and Chadwick, 1995):

- $\quad$ synchronous wave measurements between offshore and inshore measurement

- $\quad$ high tide; to have reasonable depth of water in the area behind breakwaters

- small values of the reflection coefficient measured offshore

From this set, a subset of six records representing wind, bimodal and swell conditions measured in October 1994 was chosen. The wind spectra 64, 69 and 75 have broad frequency and directional spectra and are comparable to case B1 in the laboratory experiment. The swell spectra 72 and 73 with narrow frequency and moderately broad directional spectra can be identified with the N2 case. The bimodal spectra are closer to the B1 laboratory case. A summary of offshore wave field conditions and the associated inshore wave field conditions for these data sets is given in Table 4.

The parameters such as the peak period, the mean period and the incident wave height were derived from offshore and inshore directional spectra and frequency spectra. The 
mean direction and directional spreading were determined using recommendations by Frigaard et al. (1997). The reflection coefficients for the peak and mean wave period (independent of the wave direction) at the toe of the breakwater were calculated by using the formula of Davidson et al. (1996). This formula is derived on the basis of the measurements taken at the same site. The reflection from the beach has been derived from directional analysis of the surface elevation measured in the embayment shoreward of the gap using the following equation:

$$
K r^{2}=\frac{E_{r}}{E_{i}}
$$

where $E_{r}$ and $E_{i}$ are reflective and incident energy respectively. The Ursell number is calculated by using the Guza and Thornton (1980) definition.

\subsection{Computational set up}

The same computational area as used by Ilic (1999) of $2000 \mathrm{~m}$ (longshore) x $2000 \mathrm{~m}$ (cross-shore), with grid spacing of $4 \times 4 \mathrm{~m}$ was chosen (Figure $5 \mathrm{~b}$ ). An additional extension was added at each side to reduce the lateral boundary effect. The model offshore bathymetry is based on the surveys provided by Robert West and Partners (1991) while the shoreline bathymetry is based on the aerial survey taken in September 1994 (Axe at al., 1996). The offshore incoming boundaries were set-up at the location of the offshore array. The measured offshore directional spectra were taken as input at all offshore boundary grid points. Forty-eight frequency and thirty-six directional components were used to simulate the directional spectra for all cases. In order to reduce the computation time, the computed directional spectra over the bathymetry 
without breakwaters were implemented at the (left) lateral boundary of the extended computational domain.

Five different model runs for each data set were performed, RUN1-RUN5. First, the model was run without diffraction, reflection and transmission (RUN1). This was followed by a simulation of diffraction around impermeable and non-reflective structures without reflection and transmission (RUN2). The number of convolution steps for each case was chosen on the basis of the diffraction tests given in Section (4.2). For example, for wind waves (data set 64) only one step was used, while for swell (data set 73) 11 steps were required. The third run incorporated diffraction and reflection from the breakwaters but no transmission (RUN3). Here, the breakwaters were replaced by reflective obstacles in the computational domain (Booij et al., 2004) representing the field breakwater's layout as closely as possible. The fourth run (RUN4) included diffraction and transmission. The transmission coefficients of $20 \%$ were estimated from the graphs derived on the basis of the field measurements at the same site in Elmer in 1996/1997 (Simmonds et al. 1997). The fifth (RUN5) and final test included reflection and transmission at the obstacles.

Dissipation of wave energy due to the depth-induced breaking was calculated using the Battjes and Jansen (1978) formulation in all five runs. It should be noted that none of these tests included beach reflection, bottom friction and wave-current interaction. The bottom friction and current magnitude and direction were not known as they were not measured during this field campaign. Instead, sensitivity tests with beach reflection, friction and currents have been additionally performed to test their impact on the wave transformation and are discussed in Section 4.4. 


\subsection{Model results comparison}

Figure 6 a,b,c shows the results for all model runs by plotting the ratio between computed and measured wave heights for the three inshore positions. Differences between predicted and measured wave heights are between $0-50 \%$. The largest differences are observed for swell wave conditions at the position in the lee of the breakwater (Figure 6a). In the position shoreward of the breakwater gap, there is better agreement (within 10-15\%) between measured and calculated wave heights (Figure 6b). At the third location in the breakwater gap (Figure 6c) quite good agreement between predicted and measured wave heights was obtained again $(\sim 11 \%)$. Overall, the best agreement between predicted and measured wave heights was obtained for the wind spectra, data sets 64,69 and 75 followed closely by bimodal data sets 66 and 67 . Generally RUN2-RUN5 gave better estimates than RUN1. Additionally, results obtained by the MSE model with settings given by Ilic (1999) are plotted in the same figure. SWAN predicts wave heights better in the gap and at the position shoreward of the gap (1/2 the MSE rms) and equally well at the position in the lee of the breakwater. A detailed comparison of the calculated and measured frequency and directional spectra for different tests is given below.

\subsubsection{WIND SPECTRA}

For the wind cases 64,69 and 75, inshore frequency spectra retain the same shape with the same peak frequency as those offshore. This is illustrated in Figure 7a for case 64. Predicted spectra with RUN1, RUN2 and RUN4 are compared to those measured at three inshore locations in Figure $7 b, c, d$. The shape of frequency spectra and peak frequencies are well reproduced. The higher values of total energy, seen in Figure 6, are due to overestimation of energy at higher frequencies for locations in the gap, and at the 
peak frequency shoreward of the gap. The difference between the measured and predicted spectra decreased in RUN2 and RUN4. The best agreement between computed and measured spectra was obtained in the lee of the breakwater for RUN4 (Figure 7d).

From the plots of the measured offshore and inshore directional spectra for data set 64 (Figures 8a,b), it can be seen that the peak frequency remains the same while the inshore direction changed to the shore normal. The model reproduced well a shift in main direction ( $8^{\circ}$ difference). Despite an increase in the directional spread when diffraction and transmission are included (RUN2, RUN4), it is generally less than half of the measured values in all tests. Although good agreement is observed for data sets 69 and 75 (Ilic et al., 2007), the best prediction in the lee of the breakwater was for data set 64 . In this case the incident waves come from the SE and directly radiate into the area where the measurements were taken.

\subsubsection{BIMODAL SPECTRA}

The frequency spectra for bimodal-sea cases 66 and 67 have two distinctive peaks at a low frequency of around $0.1 \mathrm{~Hz}$ (swell) and at a high frequency of around $0.2-0.25 \mathrm{~Hz}$ (wind-sea). The inshore spectral densities for higher frequencies are reduced whereas there is an increase in spectral densities for lower frequencies. There is also a shift of energy density from peak frequencies to lower neighbouring frequencies. This is illustrated in Figure 9a for case 67. From comparison plots between the measured and predicted inshore spectra in Figure 9b,c,d, it can be seen that the shape and the peak frequency of the 'wind spectra' are well predicted. However, the downwards shift of the swell peak frequency is not predicted. There is also an overestimation of spectral energy 
densities for higher frequencies at all locations and an underestimation of the swell energy density in the lee of the breakwater for all tests.

The offshore and inshore measured directional spectra are given in Figure $10 \mathrm{a}, \mathrm{b}$. The inshore spectrum is essentially single-peaked whereas the offshore is double peaked. There is a shift of the swell peak frequency to lower frequency and a shift in direction to the shore normal in the inshore spectrum. There is also the presence of some reflection for the peak frequency inshore, which was not modelled. As seen in Figure 9 the model did not reproduce the frequency shift but it did reproduce a directional shift with a $4^{\circ}$ difference. Although, the estimated directional spectra with RUN2 (Figure10c) and RUN4 (Figure 10d) are similar, the directional spreading increased slightly for RUN4. Similar differences between predicted and measured spectra are observed for data set 66, not shown here (Ilic et al., 2007).

\subsubsection{SWELL SPECTRA}

For swell cases 72 and 73, most of the energy is contained in the low frequencies (less than $0.1 \mathrm{~Hz}$ ). There are considerable changes in the shape of the frequency spectra between the offshore and inshore as shown for case 73 (Figure 11a). Comparison of predicted and measured spectral energy densities for case 73 at three locations is given in Figure 11b,c,d. Spectral energy densities are underestimated at all locations with the largest difference found in the lee of the breakwater. Overall, the differences were smallest for RUN1. As in the bimodal cases, the model tests do not reproduce the downwards shift in the peak frequency.

Figure 12a,b shows the measured offshore and inshore directional spectra for dataset 73 . The offshore spectrum has a narrow frequency and directional spread. Inshore, the peak frequency is lower than offshore and direction has changed towards the shore normal, 
while the directional spread and the reflection increased. The corresponding predicted directional spectra for RUN2 and RUN4 are given in Figure $12 \mathrm{c}, \mathrm{d}$. The peak frequency shift in the inshore is not predicted, but the mean direction is well-predicted, and is best in RUN2 ( $4^{\circ}$ difference). The directional spreading is much lower than measured and typically less than $1 / 3$ of the measured value for all runs. The reflection detected inshore (Figure 12b) is not modelled. The predicted frequency and directional spectra for swell dataset 72, not shown here, were much closer to those measured than for data set 73 , despite a mismatch in the peak frequency. Some of the observed difference can be associated with the different number of convolution cycles used when predicting data sets 72 and 73, which were 6 and 11 respectively.

\subsection{Sensitivity tests}

Further tests were performed to investigate the inclusion of beach reflection, increased wave transmission, friction and currents on model predictions. The influence of beach reflection was tested for data set 73 , for which a large amount of reflection had been detected inshore. The obstacles, as in the case of breakwater reflection, were implemented at two grid spacings from the shoreward boundary in order to observe the effect of reflection in the embayment. Three different beach reflection coefficients were chosen: one derived from measurements $(0.55)$ by the expression given in (5) and two of slightly higher values (0.83 detected for peak frequency and 0.99). By increasing the reflection the predicted wave heights increased in both locations in the embayment.

Figure 13 shows the results for an average reflection coefficient of 0.83 , which is close to the reflection coefficient for the frequencies containing most of the energy (Fig 13d). The inclusion of beach reflection increased the energy at both measurement locations in the embayment (Figure 13a,b). Also, the reflection can now be clearly seen in the 
directional spectrum at the position shoreward of the gap (Figure 13c). These tests proved that beach reflection has an important influence on wave height distributions behind breakwaters, and it would be desirable to include a frequency dependent reflection coefficient into the model.

Sensitivity tests were performed with data sets 64 and 73, by increasing the transmission through the breakwater first to $40 \%$ and then $60 \%$. The model results with $20 \%$ transmission (RUN4) matched best the measured frequency spectra and wave heights for data set 64 . In contrast, the agreement between the computed and measured frequency spectra is best for the higher transmission of $60 \%$ for data set 73 (Figure 14a,b). Clearly, frequency dependent transmission coefficients are required to correctly model the low frequency case.

Additional sensitivity tests that looked at the influence of friction on model predictions (Ilic et al., 2007) showed that friction has minor effect for these cases. The role of wave-current interaction was examined by including wave-induced and tidal currents in the diffraction resolving model SWAN. The wave-induced currents were computed by Delft3D model (Lesser et al., 2004) with the standard settings, as there were no measurements of the currents available for calibration. The predicted wave induced currents were rather small (up to $7 \mathrm{~cm} / \mathrm{s}$ ) and did not have a significant effect on predicted wave height and directional spectra.

Tidal currents were simulated using the tidal current model in Delft3D with boundary conditions obtained from the Continental Shelf Model (CSM) (Gerritsen et al., 1995). The tidal currents in the embayment predicted for the periods when the wave measurements were taken were up to $27 \mathrm{~cm} / \mathrm{s}$. The wave-tidal current interaction was simulated only for data set 64 and 73. Figure 14c,d shows a comparison between the 
frequency spectra, predicted with and without tidal interaction, in the gap and in the lee of the breakwater with the largest tidal currents for data set 73 . Due to tidal interaction, there is a slight increase of energy in the gap and decrease of energy in the lee of the breakwater. A very slight shift of peak frequency and skewing of the spectrum to lower frequencies is observed due to tidal interaction in the frequency spectra computed in the gap. Also, a change in the peak direction has been detected in the computed directional spectrum at the position shoreward of the gap.

In summary the wave height predictions were better for wind-sea than swell-sea conditions. For wind-sea waves with broad directional distributions, part of the energy propagates directly into the shadow zone and is not affected by diffraction processes. Besides refraction-diffraction processes, beach reflection and transmission appear to influence the wave transformation behind the breakwaters. The model predicted well the shift in the main direction inshore. However, it failed to predict the shift in the peak frequency and directional spreading. Simulations with the lumped triad approximation (LTA) did not change results (Ilic et al., 2007).

\section{Discussion}

A detailed comparison of the calculated and measured directional spectra for different RUNS can help to elucidate the important processes that influence the transformation of directional wave spectra. It is clear that diffraction processes are less pronounced for broad directional spectra and hence for sea-wave conditions. Lower-frequency swell waves partially reflect from the steep upper beach as seen from plots of inshore directional spectra (Figure 12b). This can cause a spatial modulation of the spectral energy due to a phase coupling of the incident and reflected waves (Elgar at al., 1997). Reflection from the breakwater and transmission through the breakwater is more 
pronounced for lower gravity frequencies, while dissipation on the breakwaters is more pronounced for higher frequencies (Simmonds et al., 1997, Ilic et al., 2005). Hence, in addition to refraction and diffraction processes, reflection from the beach and transmission seem to play a significant role in transformation of swell-sea waves behind breakwaters. More consideration may need to be given to the frequency dependent transmission and reflection, and to alternative frequency dependent wave dissipation in the model.

The wind-sea waves undergo milder transformation than bi-modal or swell waves (Figures 7a, 9a, 11a). For moderately energetic swell waves $(\mathrm{Hs}=0.6-0.8 \mathrm{~m})$, breaking occurs close to the shore and nonlinear interactions prior to wave breaking could be responsible for the observed energy shift between frequencies (data set 72 and in particular 73). This corresponds to higher Ursell numbers at two positions in the embayment for those waves. The observed secondary peaks at the harmonics of the spectral peak frequency can develop due to the non-linear processes during wave shoaling (Elgar et al., 1993). The very little energy detected at lower frequencies (e.g. data set 73) can be produced due to the interference between two neighbouring highfrequency waves in shallow water (Longett-Higgins and Stewart, 1962, Goda, 1975, Guza and Thornton, 1985). Bispectral analysis by Ilic (1999) showed phase coupling of the neighbouring frequency bands, indicating energy transfer between the peak frequency and higher and lower harmonics due to triad interactions. However, these processes have little effect in this study.

In addition, interaction with opposing or following wave-induced and tidal currents can cause change in wave height and also affect the shape of the frequency spectra (Haller at al., 1997, Ilic et al., 2005). However in this case, wave-induced currents had a very 
little effect on the wave heights and spectra at the measured location. The stronger tidal currents did have an effect on the shape of the frequency spectrum, but this does not completely explain the observed redistribution of energy by frequency. It is interesting that for all cases with peaks at swell frequencies offshore (data sets 66, 67, 72 and 73), the peaks shift downwards to correspond to a period of $12.21 \mathrm{~s}$ inshore. This period is close to a seiching period of the embayment. Hence, it is possible that seiching of the basin was occurring at inshore positions, which could affect the shape of frequency spectra. Other minor effects can be caused by processes such as wave overtopping and local wind.

Although great care was taken when data were measured and analysed, it is possible that residual measurement errors, instrument and environmental noise may still have an effect. Inevitably, there may be errors due to the settings chosen for the model. Further limitations arise from comparison with field measurements at only three positions and lack of currents and wind data. The model was tested only for conditions during high tide; and might behave differently with rising and falling tidal conditions.

\section{Conclusions}

In this paper the performance of the new phase-decoupled refraction-diffraction spectral wave model was assessed in terms of its ability to predict frequency and directional spectra. The validation of the model with laboratory data showed that the inclusion of diffraction in the model improved the estimation of wave heights in the shadow area behind the breakwater. The best agreement was observed for the directional spectrum of broad frequency and directional distribution, for which diffraction is less pronounced and also fewer instabilities are introduced due to the diffraction implementation. 
Besides the number of convolution cycles in the numerical solution for diffraction increases for larger $L / \Delta x$.

The results of the comparison between the model and field data confirmed that wave heights behind the breakwater are indeed predicted better when diffraction is included in the model. Wave heights, and the shape of frequency and directional spectra, are better reproduced for wind-sea with broad frequency and directional spectra than for a swell with narrow frequency and directional spectra. In the case of bimodal seas, the 'sea part' of the spectra is again better reproduced than the 'swell part' of the spectra. For swell waves diffraction processes are more dominant than for wind-sea waves.

These tests showed the important influence of refraction-diffraction, shoaling and wave dissipation through wave breaking processes on the frequency and directional characteristics of waves around offshore breakwaters. Beside these processes, reflection from the beach has the most influence on wave height distribution in the embayment for swell and bimodal waves. Transmission through a breakwater influences the wave height in the lee of a breakwater, while both processes influence the directional energy distribution for all sea conditions. The inclusion of frequency dependent transmission and reflection coefficients in the model would be desirable. Wave-current interactions and friction had secondary roles in this case. However, both linear and non-linear processes act simultaneously to alter the frequency and directional characteristics of nearshore waves in particular for swell waves.

It was beyond the capabilities of the model to predict the shifts in the peak frequency of the spectra for bi-modal and swell waves. The effect of currents, reflection, wave dissipation and non-linear processes on these frequency shifts remains uncertain. It is possible that these apparent shifts are due to basin seiching. The model results may need 
to be compared with results from weakly nonlinear or nonlinear model to resolve these issues. In summary, the model can accurately predict the transformation of frequency and directional spectra for wind waves and, with some caution, can be used to predict their transformation for swell waves, in intermediate water depths.

\section{Acknowledgment:}

We would like to thank Professor Marcel Stive who enabled Suzana Ilic's visit to the

Faculty of Civil Engineering and Geosciences at Technical University Delft, where this work was initiated. Also we would like to thank to Dr Michael Briggs from the Coastal Engineering Research Centre, for providing us with laboratory data and reports.

References:

Axe, P.G., Ilic, S., Chadwick, A.J., 1996. Evaluation of Beach Modelling Techniques Behind Detached Breakwaters, Proc. of 25th Inter. Conf. on Coastal Engineering, Orlando 1996, USA, ASCE, pp 2036-2047

Battjes, J.A. and Jansen, J.P.F.M.., 1978. Energy loss and set-up due to breaking of random waves, Proc. $16^{\text {th }}$ Int. Conf. Coastal Engineering, ASCE, pp 569-587.

Behrendt, L. and Jonsson, I. G., 1984. The Physical Basis of the Mild-Slope Wave Equation, Proceedings $19^{\text {th }}$ Coastal Eng. Conf., Houston, pp 941-954.

Berkhoff, J. C. W., 1972. Computation of Combined Refraction-Diffraction, Proc. $13^{\text {th }}$ Coastal Eng. Conf., Vancouver, ASCE, Vol.1, pp 471-490.

Berkhoff, J. C. W., 1976. Mathematical Models for Simple Harmonic Linear Water Wave Models, Wave Refraction and Diffraction, Phd Thesis, Techn. Univ. of Delft, pp 110

Booij, N., Haagsma, I.J.G., Holthuijsen, L.H., Kieftenburg, A.T.M.M., Ris, R.C., van der Westhuysen, A.J. and Zijlema, M., 2004. SWAN Cycle III version 40.41, User Manual, Delft University of Technology

Booij, N., Ris, R.C. and Holthuijsen, L.H., 1999. A third-generation wave model for coastal regions, Part I, model description and validation. Journal of Geophysical Research, 104 (C4), 7649-7666.

Borgman, L.E., 1990. Irregular Ocean Waves: Kinematics and Forces, In Ocean Engineering Science The Sea, Vol 9, Part A (Editied by LeMehaute, B., Hanes, D.M.), John Wiley and Sons, New York, 1-1301.

Bouws, E., Gunther, H., Rosenthal, W., and Vincent, C., 1985. Similarity of the Wind Wave Spectrum in Finite Depth Water, J. Geophys. Research, 90 (C1), pp

Briggs, M.J., Thompson, E.F. and Vincent, C.L.,1995. Wave Diffraction Around Breakwater, J. Wtrway.Port.Coast. and Oc. Engrg., ASCE, 121(1), pp 23-35.

Chadwick, A.J., Ilic, S., Helm-Petersen, J., 2000. An Evaluation of Directional Analysis Techniques for Multidirectional, Partially Reflected Waves: Part 2 Application 
to Field Data, Journal of Hydraulic Research, Vol 38, No 4, pp 253-259.

Chadwick, A.J., Pope, D.J., Borges, J., Ilic, S., 1995. Shoreline Directional Wave Spectra. Part 2. Instrumentation and Field Measurements, Proc Instn Civ Engrs, Water Maritime and Energy, Vol 112, Issue 3

Chadwick, A. J., Fleming, C., Simm, J. and Bullock, G. N., 1994. Performance Evaluation of Offshore Breakwaters - a Field and Computational Study. Proceedings Coastal Dynamics 94, ASCE, pp 950 - 961.

Copeland, G. J. M., 1985. A Practical Alternative to the "Mild-Slope" Wave Equation, Coastal Eng., 9, pp 125-149.

Davidson, M.A., Bird, P.A.D., Bullock, G.N., Huntley, D.A., 1996. A New Dimensional Number for the Analysis of Wave Reflection from Rubble Mound Breakwaters, Coastal Engineering 29, pp 93-120.

Dingemans, M. W., 1997. Water Wave Propagation over Uneven Bottoms, Part 1 Linear Wave Propagation, Advanced Series on Ocean Engineering, Vol 13, Ed Liu P L F, World Scientific, London

Dingemans, M. W., Stive, M. J. F., Kuik, A. J., Radder, A. C. and Booij, N., 1984. Field and Laboratory Verification of the Wave Propagation Model CREDIZ, Proc. 19th Int. Conf. on Coastal Engr., Houston, pp. 1178-1191

Eldeberky, Y. and Battjes, J.A., 1996. Spectral modelling of wave breaking: Application to Boussinesq equations, Journal of Geophysical Research, 101, No C1, 1253-1264.

Elgar, S., Guza, R.T. and Freilich, M.H., 1993. Observations of Non-linear Interactions in Directionally Spread Shoaling Surface Gravity Waves, J. Geophysical Research, 98/C11, pp 20299-20305.

Elgar, S., Guza, R.T., Raubenheimer B., Herbers, T.H.C. and Gallagher, E., 1997. Spectral evolution of shoaling and breaking waves on a barred beach, Journal of Geophysical Research, 102, C7, pp 15797-15805.

Frigaard, P., Helm-Petersen, J., Klopman, G., Stansberg, C.T., Benoit, M., Briggs, M.J., Miles, M., Santas, J., Schaffer, H.A. and Hawkes, P.J., 1997. IAHR List of Sea State Parameters - An Update for Multidirectional Waves, IAHR Seminar Multidirectional Waves and their Interaction with Structures, $27^{\text {th }}$ IAHR Congress, San Francisco, pp 15-24.

Gerritsen, H., de Vries, J.W., and Philippart, M.E., 1995. The Dutch Continental Shelf Model, in: D.R.Lynch and A.M.Davies, eds. AGU Coastal and Estuarine Studies, Volume 47, pp. 425-467

Goda, Y., 2000. Random Seas and Design of Maritime Structures, World Scientific, Singapore.

Goda, Y., 1998. An overview of coastal engineering with emphasis on random wave approach, Coastal Engineering Journal, Vol. 40, No 1, pp 1-21.

Goda, Y., 1975. Irregular wave deformation in the surf zone, Coastal Engineering in Japan, 18, pp 13-26.

Grassa, J.M., 1990. Directional Random Waves Propagation on Beaches, Proc. $22^{\text {nd }}$ Conf. on Coastal Eng., Delft, pp 798-811.

Guza, R.T. and Thornton, E.B., 1980. Local and shoaled comparisons of sea surface elevations, pressures and velocities, Journal of Geophysical Research, Vol 85, No 3, pp 1524-1530.

Guza, R.T. and Thornton, E.B., 1985. Observations of Surf Beat. Journal of Geophysical Research, Vol 90, No C2, pp 3161-3172.

Haller, M. C., Dalrymple, R.A. and Svendsen, I.A., 1997. Rip channels and nearshore circulation, Proceedings of ASCE Coastal Dynamics '97, Plymouth, 594-603. 
Holthuijsen, L.H., Herman, A. and Booij, N., 2003. Phase-decoupled refractiondiffraction for spectral wave models, Coastal Engineering 49, pp 291-305.

Huntley, D.A. and Davidson, M.A., 1998. Estimation of Directional Waves near a Reflector, J. Wtrway.Port.Coast. and Oc. Engrg., ASCE, Vol 124, No 6, pp 1- 8

Hurdle, D. P., Kostense, J. K. and Van den Bosch, P., 1989. Mild-Slope Model for the Wave Behaviour in and Around Harbours and Coastal Structures in Areas of Variable Depth and Flow Conditions, In Advances in Water Modelling and Measurement, pp 307-324.

Ilic, S., van der Westhuysen, A.J., Roelvink, D.J.A. and Chadwick, A.J.,2007. Study of Multidirectional wave transformation around detached breakwaters using SWAN numerical model, Internal Report, Department of Geography, Lancaster University, ISBN 978-1-86220-196-5.

Ilic, S., Chadwick, A.J. and Fleming, C., 2005.Detached Breakwaters: An Experimental Investigation and Implication for Design- Part1- Hydrodynamics. Proceedings of ICE, Maritime Engineering.

Ilic, S., Chadwick, A.J., Helm-Petersen, J., 2000. An Evaluation of Directional Analysis Techniques for Multidirectional, Partially Reflected Waves: Part 1 Numerical Investigations, Journal of Hydraulic Research, Vol 38, No 4, pp 243-253

Ilic, S., 1999. Multidirectional Sea Transformation - Field and Computational Study, PhD Thesis, SCSE, University of Plymouth, 1999.

Ilic, S. and Chadwick, A.J., 1995. Evaluation and Validation of the Mild Slope Evolution Equation Model Using Field Data. Proc. Conf. Coastal Dynamics '95, Gdainsk, Poland, ASCE, pp 149-160.

Isobe, M., 1987. A Parabolic Model for Transformation of Irregular Waves due to Refraction, Diffraction and Breaking, Coastal Engineering in Japan, Tokyo, Vol 30, pp 33-47.

Lesser, G.R., Roelvink, J.A., van Kester, J.A.T.M. and Stelling, G.S., 2004. Development and validation of three-dimensional morphological model, Coastal Engineering, 51, No. 8-9, pp 883-915.

Li, B., 1994. An Evolution Equation for Water Waves, Coastal Eng., 23, pp 227-242.

Li, B., Reeve, D. E. and Fleming, C. A., 1993. Numerical Solution of the Elliptic MildSlope Equation for Irregular Wave Propagation, Coastal Eng., 20, pp 85-100.

Longuet-Higgins, M.S. and Stewart, R.W., 1962. Radiation stress and mass transport in gravity waves, with application to surf-beats, Journal Fluid Mechanics, 13, pp 481-504.

Madsen, P.A., and Sørensen, O.R., 1992. A new form of the Boussinesq equations with improved linear dispersion characteristics. Part 2. A slowly - varying bathymetry, Coastal Engineering, 18, 183-204.

Mory, M. and Hamm, L., 1997. Wave, Set-Up and Currents around a Detached Breakwater Submitted to Regular and Random Wave Forcing. Coastal Engineering, 31, pp 77-96.

O'Reilly, W. C. and Guza, R. T., 1991. Comparison of Spectral Refraction and Refraction - Diffraction Wave Models, J.Waterw. Port. Coast. Ocean Eng., ASCE, 117, pp 199-215.

Ozkan, H.T., and Kirby, J.T., 1993. Evolution of Breaking Directional Spectral Waves in the Nearshore Zone, Proc., $2^{\text {nd }}$ Int. Symp. On Wave Measurement and Analysis, Wave '93, New Orleans, pp 849-863.

Panchang, V.G., Ge, W., Pearce, B.R. and Briggs, M.J., 1990. Numerical Simulation of irregular wave propagtion over a shoal, J. Wtrway.Port.Coast. and Oc. Engrg., ASCE, 116(3), pp 324-340. 
Peregrine, D.H., 1967. Long waves on a beach, Journal of Fluid Mechanics, 27, 815827.

Robert West and Partners, (1991). Arun District Council and National Rivers Authority Joint Coastal Defence Study.

Rogers, W.E., Kaihatu, J.M., Petit, H.A.H., Booij, N. and Holthuijsen, L.H., 2002.

Diffusion reduction in an arbitrary scale third-generation wind wave model. Ocean Engineering, 29, 1357-1390.

Simmonds, D.J., Chadwick, A.J., Bird, P.A.D. and Pope, D.J., 1997. Field Measurements of Wave Transmission through a Rubble Mound Breakwater, Proc. Conf. Coastal Dynamics '97, Plymouth, UK, ASCE, pp

Walsh, T.M., 1992. Diffraction of Directional Wave Spectra Around a Semi-Infinite Breakwater, U.S, Army Engineer Waterways Experiment station, Report CERC92-5

Wei, G. and Kirby, J.T., 1995. Time-dependent numerical code for extended Boussinesq equations, Journal of Waterway, Port, Coastal and Ocean Engineering, 121, pp 251-261.

Woo, S.B. and Liu, P. L. F., 2004. A finite element model for modified Boussinesq equations. Part I: Model development. Journal of Waterway, Port, Coastal and Ocean Engineering, ASCE, Vol 130 (1), pp 1-16.

Zijlema, M. and van der Westhuysen, A.J., 2005. On convergence behaviour and numerical accuracy in stationary SWAN simulations of nearshore wind spectra, Coastal Engineering, 52, pp 237-556. 
Figure 1: Physical model layout for Briggs' (1995) experiment; insert A shows the area were the measurements are taken and it is plotted in Figures 3 and 4.

Figure 2: Summary of convolution cycles and rms for four cases and different grid spacing. Legend: full lines show the number of convolution cycles, whereas dashed lines show rms.

Figure 3: Comparison of diffraction coefficients for Briggs' test - case B1 $\Delta \mathrm{x}=\Delta \mathrm{y}=0.2,7$ convolution cycles, $\mathrm{Lp}$ is the wavelength corresponding to the peak period $(2.25 \mathrm{~m})$. Legend: bold line - SWAN2 with diffraction, dashed line -SWAN1 without diffraction, full line - measurements.

Figure 4: Comparison of diffraction coefficients for Briggs' test - case N2 $\Delta \mathrm{x}=\Delta \mathrm{y}=0.2,13$ convolution cycles, $\mathrm{L} p$ is the wavelength corresponding to the peak period $(2.25 \mathrm{~m})$ (legend as in Figure 3$)$.

Figure 5: Elmer scheme. a) whole area; b) insert shows the area used as a computational domain. O, G, S and L stand for measurement locations offshore, in the gap, shoreward of the gap and lee of the breakwater, respectively.

Figure 6: Ratio of estimated over measured wave heights: a) lee of the breakwater, b) shoreward of the gap; c) in the gap for RUN1-RUN5 and the mild-slope model.

Figure 7: Measured and computed normalised energy density spectra for wind-sea data set $64-$ a) measured spectra at four locations; b) comparison of measured and estimated in the gap; c) comparison of measured and estimated shoreward of the gap; d) comparison of measured and estimated in the lee of the breakwater. Legend: FMO stands for measured offshore, FMG stands for measured in the gap, FMS stands for measured shoreward of the gap and FML stands for measured in the lee of the breakwater.

Figure 8: Measured and computed offshore and inshore directional spectra for wind-sea data set 64: a) measured offshore; b) measured inshore; c) computed inshore RUN2; d) computed inshore RUN4. Legend: all normalised to the maximum energy density in $\mathrm{m}^{2} / \mathrm{Hz} / \mathrm{deg}$, contours in range $0: 0.1: 1$.

Figure 9: Measured and computed normalised energy density spectra for bimodal data set $67-$ a) measured spectra at four locations; b) comparison of measured and estimated in the gap; c) comparison of measured and estimated shoreward of the gap; d) comparison of measured and estimated in the lee of the breakwater (legend as in Figure 7).

Figure 10: Measured and computed offshore and inshore directional spectra for bimodal data set 67: a) measured offshore; b) measured inshore; c) computed inshore RUN2; d) computed inshore RUN4 (legend as in Figure 8).

Figure 11: Measured and computed normalised energy density spectra for swell data set 73 - a) measured spectra at four locations; b) comparison of measured and estimated in the gap; c) comparison of measured and estimated shoreward of the gap; d) 
comparison of measured and estimated in the lee of the breakwater (legend as in Figure 7).

Figure 12: Measured and computed offshore and inshore directional spectra for swell data set 73: a) measured offshore; b) measured inshore; c) computed inshore RUN2; d) computed inshore RUN4 (legend as in Figure 8).

Figure 13: Influence of beach reflection on energy density predictions for swell data set 73: a) shoreward of the gap; b) lee of the breakwater; c) computed directional spectrum $\left.\left(\mathrm{m}^{2} / \mathrm{Hz} / \mathrm{deg}\right) ; \mathrm{d}\right)$ comparison of measured and predicted frequency dependent reflection coefficients plotted over normalised measured and predicted spectra. Legend: RUNBR stands for sensitivity tests with reflection $=0.83$ at two grid spacing from the boundary, MRC stands for measured frequency dependent reflection coefficient, CRC stands for computed frequency dependent reflection coefficient, FMS and FML as in Figure 7.

Figure 14: Influence of transmission and tidal currents on energy density predictions for swell data set 73: influence of transmission a) shoreward of the gap; b) lee of the breakwater; comparison of spectra with and without tidal currents c) in the gap and d) lee of the breakwater. Legend: RUNT1, RUNT2 and RUNTC are sensitivity tests with transmission coefficient 0.4 and 0.6 , and with tidal currents, respectively. 


\begin{tabular}{l|ll}
\hline Case & $\begin{array}{l}\text { Incident Wave Conditions } \\
\text { Description }\end{array}$ & \\
\hline N1 & Broad Frequency Distribution & Narrow Directional Spread \\
N2 & Narrow Frequency Distribution & Narrow Directional Spread \\
B1 & Broad Frequency Distribution & Broad Directional Spread \\
B2 & Narrow Frequency Distribution & Broad Directional Spread \\
\hline
\end{tabular}

Table 1 Description of laboratory simulated wave conditions 


\begin{tabular}{|c|c|c|c|c|c|c|}
\hline \multirow[b]{4}{*}{ Case } & & & & & \multicolumn{2}{|c|}{ Wrapped Normal } \\
\hline & \multicolumn{4}{|c|}{ TMA Frequency Distribution } & $\begin{array}{l}\text { Directional } \\
\text { Function }\end{array}$ & Spreading \\
\hline & $H_{s}$ & $T_{p}$ & & & $\theta_{m}$ & $\sigma_{m}$ \\
\hline & $\mathrm{cm}$ & sec & $\alpha$ & $\gamma$ & degrees & degrees \\
\hline N1 & 7.75 & 1.3 & 0.0144 & 2 & 0 & 10 \\
\hline N2 & 7.75 & 1.3 & 0.0044 & 20 & 0 & 10 \\
\hline B1 & 7.75 & 1.3 & 0.0144 & 2 & 0 & 30 \\
\hline $\mathrm{B} 2$ & 7.75 & 1.3 & 0.0044 & 20 & 0 & 30 \\
\hline
\end{tabular}

Table 2 Parameters for TMA spectra and directional wrapping function (where $\alpha$ is Philip's constant and $\gamma$ is peak enhancement factor) 


\begin{tabular}{l|ccccccc}
\hline & Model & Grid 1 & Grid 2 & Grid 3 & Grid 4 & $\begin{array}{c}\text { Ilic } \\
(1999)\end{array}$ & $\begin{array}{c}\text { Walsh } \\
(1992)\end{array}$ \\
\hline N1 & SWAN1 & 0.193 & 0.178 & 0.170 & 0.166 & & \\
& SWAN2 & 0.127 & $\mathbf{0 . 1 0 3}$ & 0.109 & 0.104 & 0.029 & 0.025 \\
N2 & SWAN1 & 0.224 & 0.210 & 0.196 & 0.188 & & \\
& SWAN2 & 0.159 & 0.134 & 0.123 & $\mathbf{0 . 1 2 2}$ & 0.047 & 0.029 \\
B1 & SWAN1 & 0.056 & 0.045 & 0.063 & 0.071 & & \\
& SWAN2 & 0.039 & $\mathbf{0 . 0 2 3}$ & 0.053 & 0.066 & 0.111 & 0.042 \\
B2 & SWAN1 & 0.086 & 0.077 & 0.098 & 0.106 & & \\
& SWAN2 & 0.067 & $\mathbf{0 . 0 5 6}$ & 0.088 & 0.094 & 0.124 & 0.075 \\
\hline
\end{tabular}

Table 3 The rms values for all SWAN runs compared with values obtained by Walsh (1992) and Ilic (1999) 


\begin{tabular}{|c|c|c|c|c|c|c|c|c|c|c|c|c|c|c|c|c|c|c|c|}
\hline \multirow{3}{*}{\begin{tabular}{|l} 
Case \\
\end{tabular}} & \multirow{3}{*}{ Set } & \multicolumn{9}{|c|}{ OFFSHORE } & \multicolumn{9}{|c|}{ INSHORE } \\
\hline & & $T_{p}$ & $\theta_{p}$ & $R_{p}$ & $T_{m}$ & $\theta_{m}$ & $R_{m}$ & $S$ & $H_{i}$ & $W D$ & $T_{p}$ & $\theta_{p}$ & $T_{m}$ & $\theta_{m}$ & $R$ & $S$ & $H_{i}$ & $W D$ & $U r$ \\
\hline & & {$[\mathrm{s}]$} & {$[\mathrm{deg}]$} & & {$[\mathrm{s}]$} & {$[\mathrm{deg}]$} & & {$[\mathrm{deg}]$} & {$[\mathrm{m}]$} & {$[\mathrm{m}]$} & {$[\mathrm{s}]$} & {$[\mathrm{deg}]$} & {$[\mathrm{s}]$} & {$[\mathrm{deg}]$} & & {$[\mathrm{deg}]$} & {$[\mathrm{m}]$} & {$[\mathrm{m}]$} & \\
\hline Wind & 64 & 5.7 & -66 & 0.37 & 4.19 & -68.6 & 0.32 & 32.05 & 1.02 & 7.31 & 5.7 & -78 & 4.02 & -82.3 & 0.41 & 30.56 & 0.55 & 3.33 & 0.16 \\
\hline & & & & & & & & & & & & & & & & & 0.6 & 2.82 & 0.24 \\
\hline & & & & & & & & & & & & & & & & & 0.93 & 4.24 & 0.16 \\
\hline Wind & 69 & 5.7 & -90 & 0.36 & 4.5 & -80.7 & 0.33 & 28.62 & 1.19 & 7.57 & 5.7 & -90 & 4.65 & -86.7 & 0.31 & 28.13 & 0.88 & 3.5 & 0.25 \\
\hline & & & & & & & & & & & & & & & & & 0.8 & 2.99 & 0.32 \\
\hline & & & & & & & & & & & & & & & & & 1.3 & 4.41 & 0.18 \\
\hline Wind & 75 & 5.96 & -102 & 0.36 & 4.84 & -101 & 0.33 & 26.15 & 1.3 & 7.31 & 6.58 & -90 & 4.76 & -89.7 & 0.31 & 28.19 & 0.93 & 3.18 & 0.44 \\
\hline & & & & & & & & & & & & & & & & & 0.56 & 2.64 & 0.50 \\
\hline & & & & & & & & & & & & & & & & & 1.14 & 4.04 & 0.37 \\
\hline Bimodal & 66 & $13.5 / 4.84$ & -90 & $0.55 /$ & 5.53 & -75.2 & 0.37 & 29.52 & 0.81 & 7.5 & 12.2 & -90 & 9.59 & -88.6 & $0.67^{*}$ & 35.00 & 0.63 & 3.47 & 1.02 \\
\hline & & & & & & & & & & & & & & & & & 0.54 & 2.96 & 1.02 \\
\hline & & & & & & & & & & & & & & & & & 0.84 & 4.37 & 0.70 \\
\hline Bimodal & 67 & $4.5 / 10.26$ & -66 & $0.33 /$ & 4.63 & -75.4 & 0.34 & 29.40 & 0.96 & 7.46 & 12.2 & -90 & 6.24 & -86.7 & $0.53^{*}$ & 31.09 & 0.63 & 3.41 & 1.02 \\
\hline & & & & & & & & & & & & & & & & & 0.59 & 2.91 & 1.11 \\
\hline & & & & & & & & & & & & & & & & & 0.88 & 4.31 & 0.87 \\
\hline Swell & 72 & 15.08 & -90 & 0.57 & 7.31 & -98.1 & 0.42 & 29.14 & 0.83 & 7.43 & 11.2 & -90 & 7.48 & -92.3 & 0.64 & 32.02 & 0.68 & 3.32 & 0.92 \\
\hline & & & & & & & & & & & & & & & & & 0.58 & 2.79 & 0.94 \\
\hline & & & & & & & & & & & & & & & & & 0.93 & 4.19 & 0.56 \\
\hline Swell & 73 & 9.5 & -90 & 0.48 & 7.26 & -97.7 & 0.43 & 26.88 & 0.62 & 7.46 & 12.2 & -90 & 9.02 & -91.1 & 0.66 & 32.09 & 0.7 & 3.35 & 1.12 \\
\hline & & & & & & & & & & & & & & & & & 0.52 & 2.82 & 0.98 \\
\hline & & & & & & & & & & & & & & & & & 0.9 & 4.22 & 0.75 \\
\hline
\end{tabular}

Table 4 Summary of offshore and inshore wave parameters where: $T_{p}$ is the peak period; $\theta_{p}$ is the principal direction, incident from $0^{\circ}$ to $-180^{\circ}$ where $-90^{\circ}$ refers to South and reflected from $0^{\circ}$ $180^{\circ}$ where $90^{\circ}$ refers to North; $R_{p}$ is the reflection coefficient calculated at the toe of the breakwater for $T_{p} ; T_{m}$ is the mean period; $\theta_{m}$ is the mean direction; $R_{m}$ is the reflection coefficient calculated at the toe of the breakwater for $T_{m}$; $S$ is the directional spreading; $H_{i}$ is the incident significant wave height from MLM analysis; WD is the offshore water depth, $\mathrm{R}$ is beach reflection coefficient and Ur is Ursell number. Inshore parameters are given for 3 positions, first shoreward of the gap, second for the lee of the breakwater and third for the gap. 